\title{
EXCHANGE FEMORAL NAILINGS AT KENYATTA NATIONAL HOSPITAL
}

H. O. Ong'ang'o, MMed(Surg), MSc Ortho(London),FCS-ECSA, Consultant Orthopaedic and Trauma Surgeon, Orthopaedics Department, Kenyatta National Hospital and Honorary Lecturer, Department of Orthopaedics Surgery, College of Health Sciences, University of Nairobi, P.O. Box 20723-00202, Nairobi, Kenya, P. Wabomba, MMed(Surg.), FRCS (Edin), Honorary Consultant Surgeon, Orthopaedics Department, Kenyatta National Hospital, P. O. Box 20723 - 00202, Nairobi, Kenya

Correspondence to: Dr. H. O. Ong'ang'o, P.O. Box 20723-00202, Nairobi, Kenya. E-mail: herbertongango@ yahoo.com.

\section{ABSTRACT}

Background: Intramedullary nailing is the method of choice in the treatment of acute femoral shaft fractures in adults. It is associated with a high fracture union rate and a low complication rate. Nonunion as well as its other rare complications are treated by exchange femoral nailing.

Objective: To look at the use of the Kuntscher nail in the management of femoral shaft fracture and to look at complications of Kuntscher nailing that require intramedullary nailing.

Design: This was a ten year observational study.

Setting: Ward 6D, Kenyatta National Hospital, Nairobi, Kenya.

Patients and methods: All patients admitted to ward 6D, Kenyatta National Hospital with fracture shaft of femur and treated by Kuntscher nailing between 1 st January 2001 and 30th April 2011 were followed up. Those who developed a complication requiring exchange femoral had the exchange femoral nailing performed by the authors.

Results: Over the study period, four patients underwent exchange femoral nailing.The indications for the exchange nailings were infection,two cases, malrotation, bent nail, and long Kuntscher nails. Infection coexisted with malrotation and a long Kuntscher nail. Exchange involved using both the conventional Kuntscher nail and a Russel-Taylor interlocking nail.

Conclusions: Exchange femoral nailing was undertaken in only $0.24 \%$ of Kuntscher nailings over this ten year's study period.

\section{INTRODUCTION}

Intramedullary nailing has been the standard treatment method for acute adult femur shaft fracture for decades(1). The concept of intramedullary fixation of femoral shaft fractures has gained wide acceptance (2). It has even become the preferred method of treatment of femoral shaft fractures in adults $(2,3)$. Traditionally the conventional Kuntscher nail in its various designs has surficed. Intramedullary nailing is attractive because of a small incision, minimal dissection, excellent fracture healing, and rapid patient recovery(3).The initial Kuntscher nail design lacked inter-locking screws, limiting its use to length-stable fractures of the femoral isthmus(4). Development of interlocking and reconstructiontype implants has extended the range of femoral fractures that can be treated by intramedullary nailing(4). Open fractures, as well as more proximal and more distal femoral fractures have benefited from this interlocking facility $(2,5)$. Intramedullary nail fixation has become widely accepted as the treatment of choice for femoral diaphyseal fractures since the description by Kuntscher in the early 1940s(4). Advancements in closed surgical techniques and improvements in implant design have resulted in excellent outcomes and very high union rates(4), as well as a low complication rate (6). Union rates as high as $99.1 \%$ have been reported in large series of intramedullary nailings for acute fractures (4). Nonunion following intramedullary nailing of a femur fracture is uncommon. The rate of nonunion following intramedullary nail fixation for a femur fracture is generally believed to be $2 \%$ or less (7). 
Currently, the standard treatment of a femoral nonunion that has failed initial intramedullary nail fixation is exchange nailing $(1,2,4-7)$. Other rare complications of intramedullary nail that are treated by exchange nailing include infected intramedullary nails $(4,8)$, bent intramedullary nails (9),broken solid nails and malrotational deformity (3).

\section{MATERIALS AND METHODS}

Between 1st January 2001 and 30th April 2011, the authors conducted an observational study on exchange femoral nailing in ward $6 \mathrm{D}$ (An orthopaedic unit) of the Kenyatta National Hospital in Nairobi, Kenya. All patients who were admitted to ward 6D, Kenyatta National Hospital between 1st January 2001 and 30th April 2011, and had fracture femur and were subsequently treated by intramedullary Kuntscher. Nailing were followed up. All Kuntscher nailings were performed in an open manner. Those who developed complications requiring exchange femoral nailing had the exchange femoral nailing performed by the authors. During the study period, totalling upto ten years, four patients required to undergo exchange femoral nailing(Table 2).Three of the patients were male while one was female. The average age at exchange nailing was 37.75 years and the interval between index nailing and exchange nailing was 269 days. All exchange femoral nailings were performed in a closed manner through the Trochanteric Scar site. Two patients had exchange of Kuntscher nails for Kuntscher nails, while the other two had Russell Taylor interlocking femoral nails in exchange for the Kuntscher nails. Appropriate radiographs were taken before the initail Kuntscher nails, after the Kuntscher nailing and after the exchange femoral nailing.

\section{RESULTS}

TABLE 1

Kuntscher nailings performed in ward 6D 20012011(30th April 2011)

\begin{tabular}{lc}
\hline Year & $\begin{array}{c}\text { No. of Kuntscher } \\
\text { nails performed }\end{array}$ \\
\hline 2001 & 124 \\
2002 & 158 \\
2003 & 157 \\
2004 & 100 \\
2005 & 114 \\
2006 & 145 \\
2007 & 235 \\
2008 & 206 \\
2009 & 185 \\
2010 & 146 \\
$2011(1 / 1 / 2011-30 / 4 / 2011)$ & 56 \\
\hline Total & 1626
\end{tabular}

TABLE 2

Patients details

\begin{tabular}{|c|c|c|c|c|c|c|c|c|}
\hline Case & Age & Sex & $\begin{array}{l}\text { Date of } \\
\text { 1st nail }\end{array}$ & $\begin{array}{l}\text { Date of } \\
\text { exchange } \\
\text { nail }\end{array}$ & $\begin{array}{l}\text { Interval } \\
\text { (Days) }\end{array}$ & $\begin{array}{l}\text { Type of } \\
1 \text { st nail }\end{array}$ & $\begin{array}{l}\text { Type of } \\
\text { exchange } \\
\text { nail }\end{array}$ & $\begin{array}{l}\text { Indication } \\
\text { for exchange }\end{array}$ \\
\hline 1 & 45 & $\mathrm{~F}$ & $11 / 5 / 07$ & $9 / 8 / 07$ & 90 & $\begin{array}{l}\text { Kuntscher } \\
12 \times 36\end{array}$ & $\begin{array}{l}\text { Russel Taylor } \\
\text { Interlocking } \\
10 \times 36\end{array}$ & $\begin{array}{l}\text { Infected } \\
\text { K-Nail } \\
\text { malrotation }\end{array}$ \\
\hline 2 & 39 & $M$ & 16/1/06 & $12 / 5 / 06$ & 816 & $\begin{array}{l}\text { Kuntscher } \\
14 \times 32\end{array}$ & $\begin{array}{l}\text { Kuntscher } \\
15 \times 24\end{array}$ & $\begin{array}{l}\text { Infected, } \\
\text { long K-Nail }\end{array}$ \\
\hline 3 & 42 & $M$ & 20/2/09 & $12 / 5 / 09$ & 81 & $\begin{array}{l}\text { Kuntscher } \\
9 \times 36\end{array}$ & $\begin{array}{l}\text { Russel Taylor } \\
\text { Interlocking } \\
10 \times 38\end{array}$ & $\begin{array}{l}\text { Malrotational } \\
\text { deformity }\end{array}$ \\
\hline 4 & 25 & $M$ & $23 / 12 / 10$ & $22 / 3 / 11$ & 89 & $\begin{array}{l}\text { Kuntscher } \\
12 \times 36\end{array}$ & $\begin{array}{l}\text { Kuntscher } \\
12 \times 34\end{array}$ & Bent \\
\hline
\end{tabular}


Figure 1

Case 2: Initially compound fracture with both fracture edges exposed

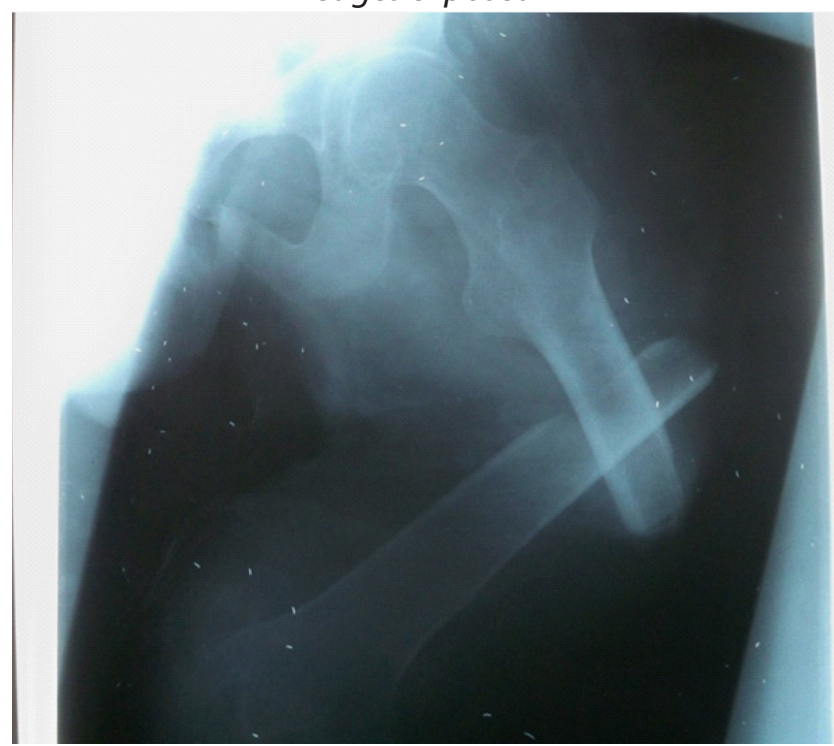

Figure 3

Case 2: Exchange Kuntscher nail (15x24)
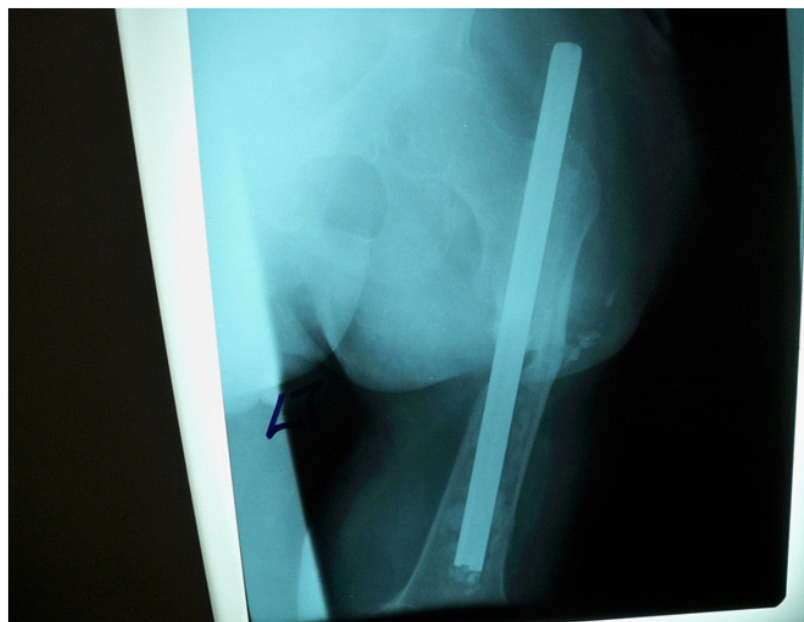

Figure 5

Case 3: Fixed with a Kuntscher nail: developed malrotational deformity

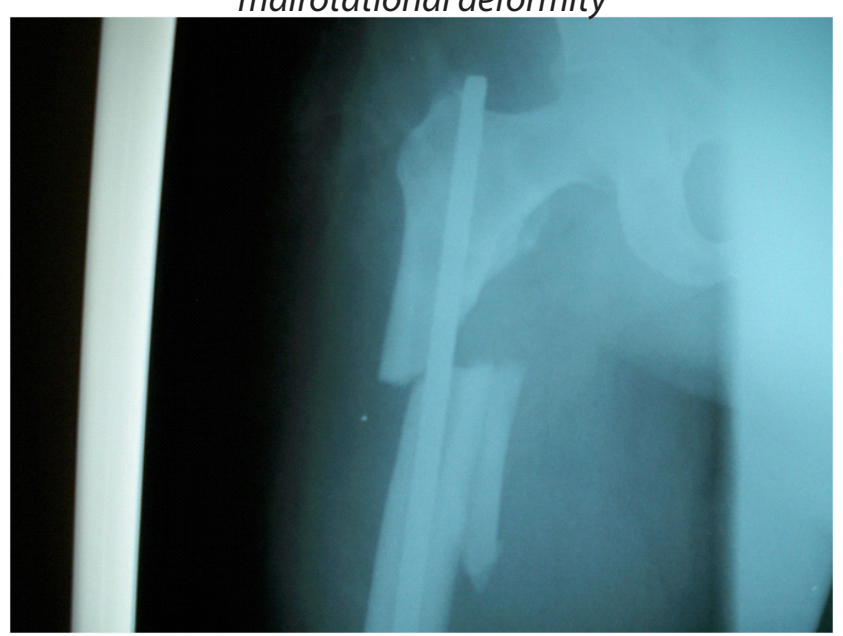

Figure 2

Case 2: Exposed bone excised,medullary cavity grafted and Kuntscher nail Inserted (14x32).

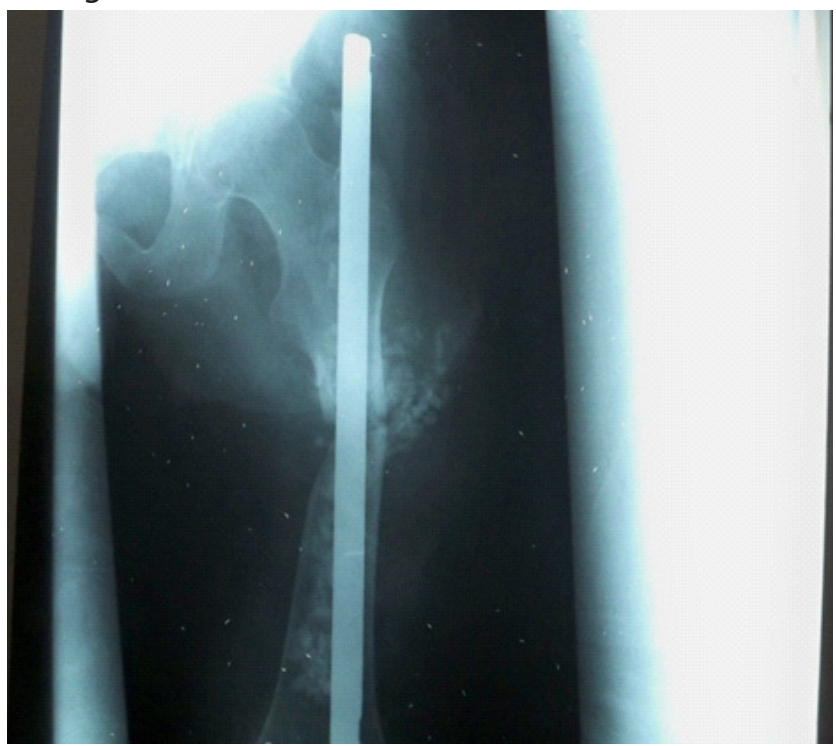

Figure 4

Case 3: Initialy comminuted fracture proximal femur
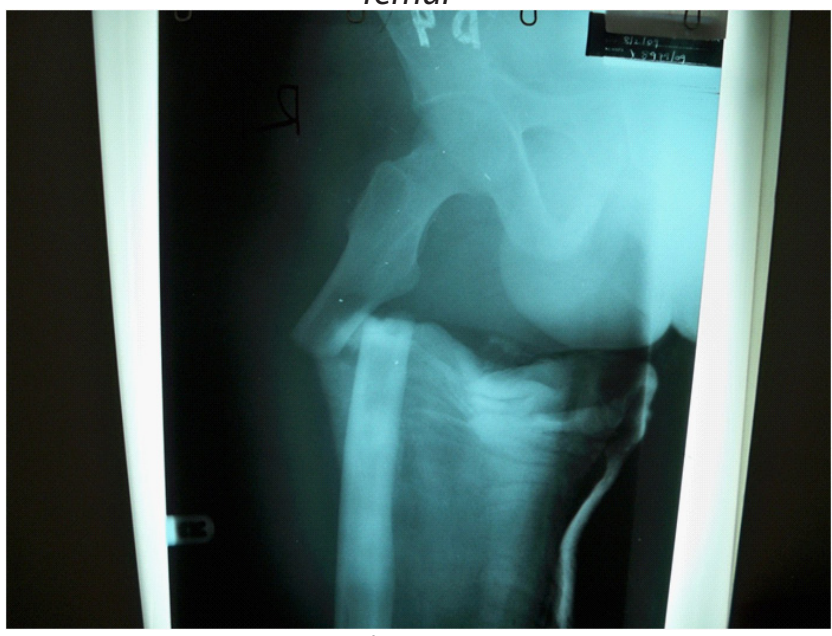

Figure 6

Case 3: Exchange Russel Taylor interlocking nail: proximal view

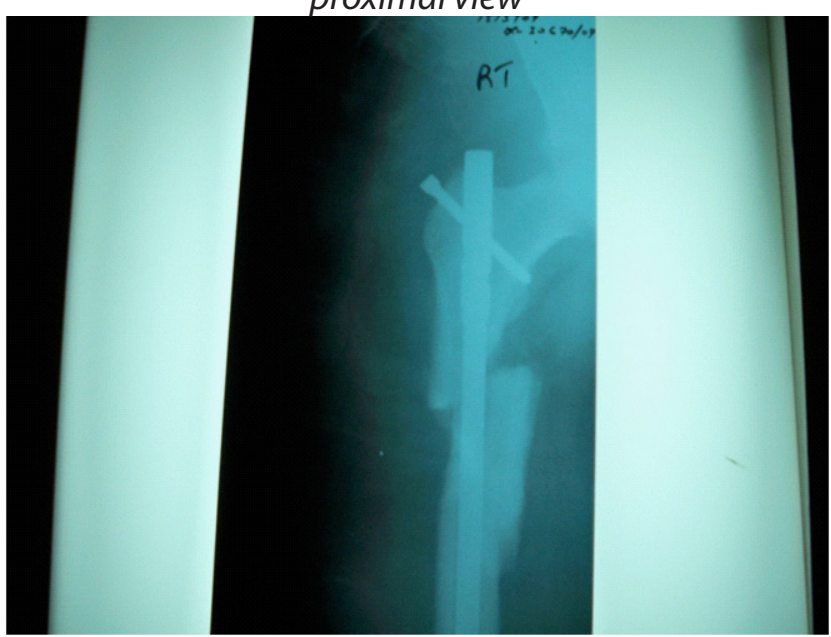


Figure 7

Case 3:Exchange Russel Taylor interlocking nail: Distal view
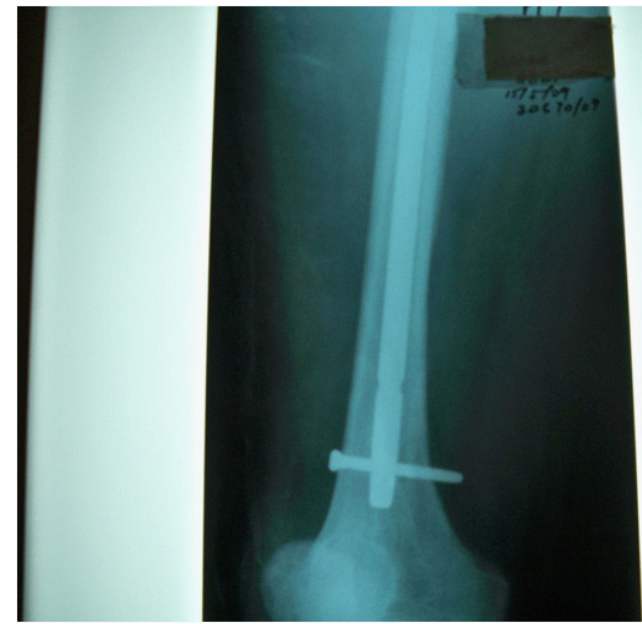

Figure 9

Case 4: Exchange Kuntscher nail

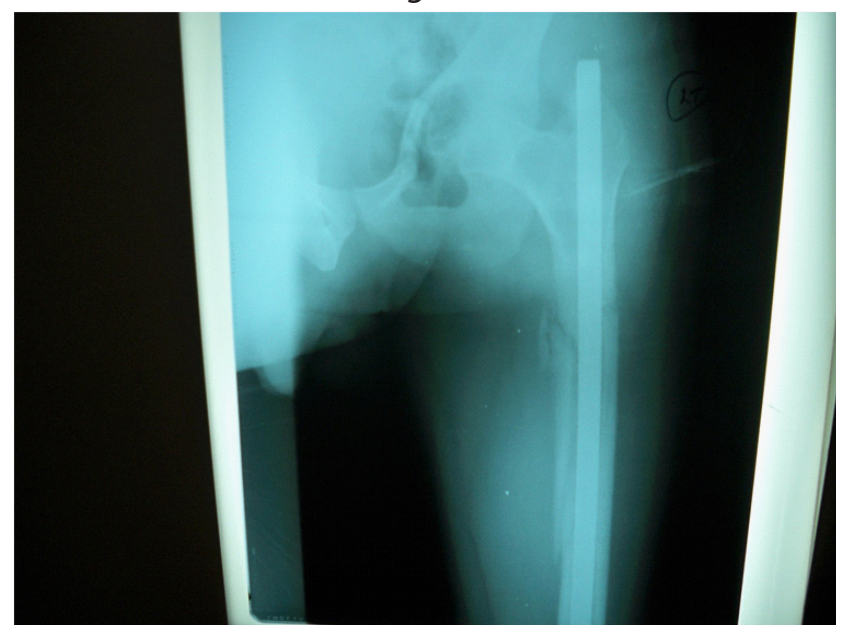

\section{DISCUSSION}

Over this study period, totalling ten years, the orthopaedic surgeons in Ward 6D, at the Kenyatta National Hospital have performed an estimated 1626 Kuntscher nailings. Upon follow-up, we have observed a total of four patients who required exchange femoral nailing . This translates to $0.25 \%$ exchange nailing rate. We proceeded to perform these exchange femoral nailings. Three of these patients were male while one was female. The commonest indications for exchange nailing were infection in two cases, malrotation, bent nail and a long nail. It is imperative to note that in the two infected intramedullary nails another complication coexisted. In one infected nail, there was also a malrotational deformity while in the other infected nail, the nail was long, protruding high above the
Figure 8

Case 4: Bent Kuntscher nail

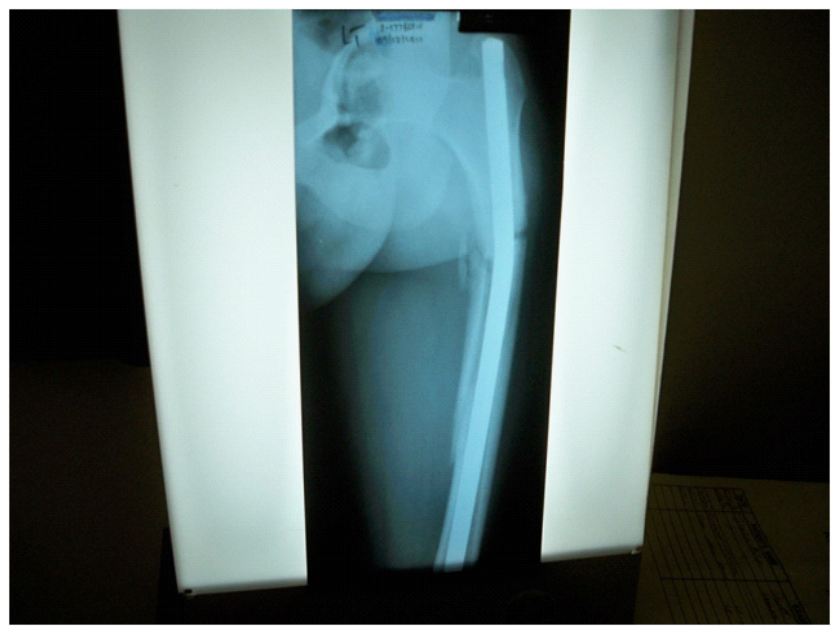

greater trochanter. This study findings contrasts sharply with all other studies in the literature which cite aseptic non union as the leading indication for exchange femoral nailing (1,2,4,5-8).The exchange rate of $0.25 \%$ compares favourably with other studies. The choice of the conventional Kuntscher nail for half the exchange cases and the RusselTaylor interlocking nail for the other half of the exchange cases is notable as some authors have advocated the ommission of interlocking screws in exchange femoral nailing $(4,8)$.The technical aspects involved closed nailing in all the exchanges. The challenges encountered were variable with the most challenging exchange being the one for the bent Kuntscher nail, while the simplest was the one for the long Kuntscher nail. The interval between index nailing and exchange nailing averaged 269 days. One patient had an inordinately long interval (816 days), whereas the others averaged 87 days. This interval compares favourably with most quoted studies in the literature which quote an interval of four months( 5 ).The patient who had a long interval between the nailings was a patient who had multiple and complex injuries right from the beginning.

\section{REFERENCES}

1. Park,J., Kim, S .G.,Yoon, H .K. et al. The treatment of nonisthmal femoral shaft nonunions with IM nail exchange versus augmentation plating.

J. Orthopaedic Trauma. 2010:24(2);89-94.

2. Pihlajamaki,H.K.,Salminen,S.T. and Bostman,O. M. The treatment of nonunions following intramedullary nailing of femoral shaft fractures. J. Orthopaedic Trauma. 2002:6; 394-402. 
3. Jaarsma, R. L.,Pakvis,D.F.M., Verdonshot,N. et al. Rotational malalignment after intramedullary nailing of femoral fractures. J. Orthopaedic Trauma. 2004;18(7);403-409.

4. Hak,D.J., Lee,S.S. and Goulet,J.A. Success of exchange reamed intramedullary nailing for femoral shaft nonunion or delayed union. J. orthopaedic Trauma. 2000: 14(3); 178-182.

5. Shroeder, J.E. Mosheiff,R. And Khoury, A. The outcome of closed, intramedullary exchange nailing with reamed insertion in the treatment of femoral shaft nonunions. J.Orthopaedic Trauma. 2009: 9;653-657.
6. Yu,C.W.,Wu,C.C. and Chen,W .J. Aseptic nonunion of a femoral shaft treated using exchange nailing. Chang Gung Med. J .2002: 25; 591-598.

7. Brinker,M.R. and O'Connor,D.P. Ilizarov compression over a nail for aseptic nonunions that have failed exchange nailing: A report of five cases. J. Orthopaedic Trauma. 2003: 17(10);668-676.

8. Brinker,M.R. and O'Connor,D.P. Exchange nailing of ununited fractures. J. Bone and Joint Surg. (AM). 2007: 89(1);177-188.

9. Banerjee, R. and Posner,M. Removal of a bent intramedullary nail with a posttraumatic sagittal plane deformity. J. Trauma. 2009: 66(5); 1500-1503. 